\title{
Analysing the drivers of irrigator drought strategies in the Southern Murray Darling Basin
}

\author{
A. Zuo ${ }^{1}, \mathrm{~S}$. Wheeler ${ }^{1} \& \mathrm{H}$. Bjornlund ${ }^{1,2}$ \\ ${ }^{1}$ CRMA, School of Commerce, University of South Australia, Australia \\ ${ }^{2}$ Economics Department, University of Lethbridge, Canada
}

\begin{abstract}
During the 2000s there has been severe and ongoing drought in the southern Murray Darling Basin, with irrigators facing considerable cuts to their water allocations corresponding with a period of falling commodity prices. Ongoing work has suggested that strategies such as the buying and selling of allocation and entitlement water, the buying and selling of land, reducing the area under irrigation, changing crops and adopting more efficient irrigation infrastructure all have played differing roles in allowing farmers to cope with drought and manage farm viability. This study analyses the influences on irrigator strategy choice during this period of drought; in particular it seeks to answer why some irrigators choose to follow mainly intensive strategies (such as buying land/water, increasing irrigation area and adopting infrastructure), while others choose predominantly defensive strategies (selling land/water and decreasing irrigation area). Two key irrigation areas are studied, the Riverland in South Australian and the Goulburn Murray Irrigation District in Victoria, using 624 telephone surveys from 2008-09. The two irrigation areas are not homogenous, and there are different influences on irrigators' strategies. Irrigator characteristics, farm characteristics, attitudes and off-farm income all play important roles.

Keywords: drought strategies, water, Australia, irrigators, intensive, defensive.
\end{abstract}

\section{Introduction}

Water scarcity is intensifying in many irrigation regions in semiarid parts of the world. This increased scarcity is partly caused by an increase in and intensification of drought events but is also policy induced as governments have 
failed to react to increasing environmental consequences of over-extraction of water for consumptive use. Reduced availability of water can potentially have significant socioeconomic impacts on irrigation dependent regions.

The severity of this impact depends both on the policies that government introduce in response to the growing environmental problems and on the strategies that irrigators follow to deal with scarcity. Improving water use efficiency, changing water management strategies and increased productivity can help offset the impact of reduced access to irrigation water. It is therefore important to understand what influences irrigators' choice of drought strategy.

There has been a severe drought in South-eastern Australia since the early 2000s, ending only in 2010. This has emphasized the need to address growing concerns over the environmental impact of over extraction of water for consumptive uses and the need for policies to rectify this problem with minimum socioeconomic impact. Since irrigation is the major water user this will inevitably result in reduced allocation of water for irrigation. In the Murray Darling Basin (MDB) the combination of the drought and policy changes has substantially reduced seasonal allocations forcing irrigators to adopt strategies to deal with scarcity.

Irrigator behaviour and decision making within the MDB during this period therefore provides a unique opportunity to study irrigators' choice of drought management strategy and to identify the factors driving such choices. This paper is based on a survey of 624 irrigators within two key regions of the MDB: the Goulburn Murray Irrigation District in Victoria and the Riverland in South Australia. The next section will briefly discuss the water reform policy development in Australia leading up the drought. The following section outlines the irrigation drought management strategies available to irrigators that have been analysed in this paper. This is followed by a discussion on methodology and data. The last two sections provide a discussion of findings and some conclusions.

\section{Some Australian water policy context}

The severe drought during the first decade of this millennium has emphasized the need to deal with environmental problems in the major rivers and the need to facilitate structural change within the irrigation industry. These problems were particularly apparent within the MDB, Australia's largest and most important river system. However, environmental problems as a consequence of lack of environmental flows in the MDB has been apparent for a long time and has led to a plethora of government policy starting with a new water policy framework set out by the Council of Australian Governments (CoAG) in 1994. This framework made water markets mandatory in all Australian states, for the first time recognized the environment as a legitimate water user and required all states to define environmental needs in their catchments and to bring extraction back to sustainable levels.

Following concern over the consequences of continued increase in water extraction with the MDB a "Cap" on water use was introduced in 1995 to 
prevent further increases in surface water diversions and to work towards environmental sustainability. In 2004 the National Water Initiative (NWI) was introduced due to the slow pace of adjustment toward securing water for the environment and introducing efficiently working water markets. The NWI and an associated agreement on addressing over allocation with the River Murray sought to achieve environmentally sustainable social and economic outcomes through water sharing plans which defined the consumptive pool within all catchments, the adoption of feasible market-based mechanisms and efficiency investments to recover water for public benefit outcomes.

The major programs that the Federal Government is implementing with regard to the irrigation is the buying of water entitlements from irrigators to provide critical environmental flows (Restoring the Balance program) and the Sustainable Rural Water Use and Infrastructure (SRWUI) program in the MDB. These are part of the Water for the Future program introduced in 2008 (encompassed a $\$ 12.9$ billion investment over 10 years, with $\$ 3.1$ billion allocated to buy water entitlements from willing sellers to secure environmental water in the Restoring the Balance program and the remainder devoted to irrigation infrastructure upgrades). As part of the SRWUI program, up to 30 June 2009 irrigators on small blocks could apply for the Small Block Irrigators Exit Grant Package [1]. South Australian irrigators have been able to apply for this grant since November 2008; however Victorian irrigators could only apply from February 2009 [2].

\subsection{The Riverland and the Goulburn Murray Irrigation District}

Irrigators in the Riverland, South Australia (SA) and the Goulburn Murray Irrigation District (GMID) in Victoria (VIC), both part of the MDB, have faced considerable stress in dealing with reduced water allocations, higher temperatures, reduced rainfall and falling commodity prices. In 2008-09 all irrigators in the MDB had their allocations reduced, with Victorian irrigators in the Goulburn and Murray systems only receiving one-third of their water entitlements by the season's end and SA irrigators received less than one-fifth. Table 1 illustrates the historical profile of end of season water allocations in three regions across the MDB.

The Riverland and the GMID have had very different experiences with drought and have very different agricultural productions which call for different drought management strategies and capacities to deal with such strategies. Irrigators within the GMID have traditionally had very high and variable allocation levels; as is apparent from Table 1 the two Victorian systems originally had higher allocations i.e. $200 \%$, and prior to the period covered in the table often had in excess of $200 \%$. Annual production and a large dairy sector have traditionally been able to benefit from this fluctuation in seasonal allocations. It can also be seen that that Victorian irrigators experienced reductions much earlier than irrigators in SA. Prior to 2006/07 seasonal allocations basically not vary in SA. Historically, SA has tried to introduce above $100 \%$ seasonal allocations, but this had little uptake since the production in SA is dominated by horticulture and viticulture which cannot easily benefit 
from access to excess water during a single season. These industries need a consistent and dependable supply. Hence, when the drought started in earnest in 2006, SA irrigators had little experience in dealing with fluctuating supply and managing an industry which had little short-term adaptive capacity. On the other hand Victorian irrigators have had long standing experience with this and a production with a high level of seasonal adaptability.

Table 1: Final water allocations in three regions of the Murray Darling Basin.

\begin{tabular}{rccc}
\hline & $\begin{array}{c}\text { Goulburn } \\
\text { System }\end{array}$ & $\begin{array}{c}\text { Victorian Murray } \\
\text { System }\end{array}$ & $\begin{array}{c}\text { SA Murray } \\
\text { System* }\end{array}$ \\
\hline $1995 / 96$ & 150 & 200 & 100 \\
$1996 / 97$ & 200 & 200 & 100 \\
$1997 / 98$ & 120 & 130 & 100 \\
$1998 / 99$ & 100 & 200 & 100 \\
$1999 / 00$ & 100 & 200 & 100 \\
$2000 / 01$ & 100 & 200 & 100 \\
$2001 / 02$ & 100 & 200 & 100 \\
$2002 / 03$ & 57 & 129 & 100 \\
$2003 / 04$ & 100 & 100 & 95 \\
$2004 / 05$ & 100 & 100 & 95 \\
$2005 / 06$ & 100 & 144 & 100 \\
$2006 / 07$ & 29 & 95 & 60 \\
$2007 / 08$ & 57 & 43 & 32 \\
$2008 / 09$ & 33 & 35 & 18 \\
$2009 / 10$ & 71 & 100 & 62 \\
\hline
\end{tabular}

* Information provided by South Australia's Department of Water, Land and Biodiversity Conservation

\section{Irrigation drought management strategies}

There are a range of management strategies irrigators can adopt to allow them to manage reduced water allocations and drought conditions. One of the major strategies to manage seasonal risks and conditions includes trading in the allocation and entitlement water markets [3]. They may also implement other strategies to reduce their exposure to risk, such as adopting irrigation efficiency improvements and management practices, reducing production of high water use crops and switching to alternative land uses. Increasing output (through buying additional water or land) is another strategy irrigators may adopt to capture additional benefits from economies of scale. Other general drought management strategies include storing fodder, flexible (and conservative) stocking rates, offfarm income, minimising environmental risk, minimising financial debt and costs, crop insurance and various taxation schemes [4].

We classified irrigators' responses to reduced water allocations and water policy changes into David's [5] typologies of business strategies, namely: intensive and defensive. Intensive strategies often require offensive attacking behaviour to improve a businesses' competitive position by increasing their 
market share, expanding their market boundaries and improving/changing their present products or services. In the context of this paper, an intensive irrigator strategy can be either 'attacking' (purchasing land, increasing irrigation area, purchasing water entitlements) or 'adopting' (having adopted irrigation efficiency improvements over the past five years). Defensive business strategies generally refer to retrenchment, divestiture or liquidation [5]. In this paper, we refer to defensive strategies as selling land, reducing irrigation area or selling water entitlements. In other words, irrigators are deploying 'defensive' strategies. Irrigator objectives with defensive strategies are generally to try to find ways of staying on the farm and within the community until retirement, however they can be a viable drought strategy to deploy to minimise costs and debt. Hence, irrigators have three overall strategies they could deploy in absolute terms, or in combination with one another, in response to recent drought in South-eastern Australia: attack, defend or adopt.

Generally in business, intensive strategies in competitive markets tend to result in more efficient businesses that adapt to the changing external environment and, therefore, are able to remain in business. Defensive strategies may result in inefficient businesses, liquidation or even exit [5]. However, this may not be the case for irrigators. There is an extensive literature in agricultural economics on the best strategies for farmers to employ in terms of drought, albeit most of this work has been done for dryland farmers. At some times, defensive strategies are the most profitable for farmers to undertake, especially in times of drought. This paper seeks to understand what drives the deployment of intensive and defensive strategies by irrigators. The aim of this paper is to explore the motivation behind irrigators' strategies. Do farmer characteristics or attitudes make a difference? Or, do the farm characteristics determine strategy choice?

\section{Methodology and data description}

\subsection{Data collection}

Mail-out surveys were posted in November 2008, followed by telephone surveys with additional attitudinal questions conducted with the respondents (plus additional irrigators) in the Riverland $(n=324)$ and the GMID $(n=300)$. The surveys collected information on: 1) personal characteristics; 2) farming operation; 3) management strategies; and 4) attitudes toward a range of issues such as tradition, community, profitability, lifestyle, environment, and technology.

\subsection{Data analysis techniques}

Factor analysis was used to identify the underlying value constructs from 56 attitudinal questions asked. Lane-Miller et al. [6] explains this in more detail. Five factors were identified: Succession, Commerce, Tradition, the Environment and Technology. The factor scores from the five constructs were used as attitudinal explanatory variables in our regression analysis. 
Table 2: $\quad$ Variable definitions.

\begin{tabular}{|c|c|}
\hline Variables & Definitions \\
\hline Intensive & Intensive index $(0=$ no strategy, $1=$ one strategy, $2=$ two or more strategies $)$ \\
\hline Defensive & Defensive index ( $0=$ no strategy, $1=$ one strategy, $2=$ two or more strategies $)$ \\
\hline Efficiency & $1=$ efficiency improvement in irrigation in the last five years; 0 otherwise \\
\hline age & Farmer's age \\
\hline male & $1=$ male; 0 otherwise \\
\hline farmyears & Number of years spent in farming \\
\hline liveyears & Number of years spent in living on a farm \\
\hline yearsremain & Number of years remained in farming \\
\hline farmfamily & $1=$ if from a farming family; 0 otherwise \\
\hline lowedu & $1=$ if highest education is Year 10 or below; 0 otherwise \\
\hline postg & $1=$ if highest education is a postgraduate degree; 0 otherwise \\
\hline successor & $1=$ if expect a family member to take over the farm; 0 otherwise \\
\hline wfp & $1=$ if have a whole farm plan; 0 otherwise \\
\hline farmsize & size of a farm five years ago, in thousand hectares \\
\hline irrisize & size of irrigation area five years ago, in thousand hectares \\
\hline tothwater & total water entitlement five years ago, in thousand MLs \\
\hline pgrape & percentage of irrigation area in grape five years ago \\
\hline pfrunut & percentage of irrigation area in fruit and nuts five years ago \\
\hline pgrazing & percentage of irrigation area in pasture for grazing five years ago \\
\hline pseed & percentage of irrigation area in pasture for seed, hay or silage five years ago \\
\hline pcereal & percentage of irrigation area in cereal five years ago \\
\hline landcare & $1=$ if a member of Landcare; 0 otherwise \\
\hline waterwatch & $1=$ if a member of Waterwatch; 0 otherwise \\
\hline ftcomfarm & 1=if a full time commercial farm; 0 otherwise \\
\hline offfarmincome & $\%$ of income from off-farm work $(0 \%, 12.5 \%, 37.5 \% 63 \%, 88 \%$ and $100 \%)$ \\
\hline contfarming & Likert scale on certainty of remaining farmer $(1=$ uncertain, $5=$ certain $)$ \\
\hline info_gov & $1=$ if information source is government; 0 otherwise \\
\hline info_pri & $1=$ if information source is private consultants; 0 otherwise \\
\hline Drip & percentage of irrigation area with drip irrigation \\
\hline reuse & percentage of irrigation area connected with a reuse system \\
\hline offfdr & percentage of irrigation area with off-farm drainages \\
\hline f1_tradition & Factor score of tradition \\
\hline f2_sucession & Factor score of succession \\
\hline f3_commercial & Factor score of commerce \\
\hline f4 environ & Factor score of environment \\
\hline f5_tech & Factor score of technology \\
\hline
\end{tabular}

Our first model of intensive strategy (attack) consisted of three potential strategies that farmers may have undertaken in the past five years: (1) purchase land; (2) buy water entitlements; and/or (3) increase irrigation area. Our first 
defensive strategy model (defend) also consisted of three potential strategies: (1) sell land; (2) sell water entitlements; and/or (3) decrease irrigation area. An index was constructed from 0 to 2 to indicate the extent to which intensive (or defensive) strategies were adopted. A value of 0 indicates no strategy was undertaken, a value of 1 indicates one strategy was undertaken; and an index of 2 indicates that at least two strategies were undertaken. The indexes of intensive and defensive strategies are ordinal outcomes and are appropriately estimated by an ordered probit model (see Greene [7] for more model details). We used a binary probit regression to model irrigators' adoption of irrigation efficiency improvements (adopt). The dependent variable is coded as 1 if more efficient irrigation infrastructure was adopted in the last five years and 0 otherwise (see Greene [7] for more model details).

The independent variables include a range of socioeconomic characteristics of farmers, farm characteristics and the five value constructs obtained from the factor analysis, with variable definitions in Table 2. In the efficiency improvement model, the irrigation infrastructure variables are not included as they are likely to be the result of improvements undertaken and not the causes of such improvements.

\section{Results and discussions}

Table 3 presents the results of ordered and binary probit regressions of the intensive and defensive strategies. The final models have reasonable fit, no problems with multicollinearity and are estimated with robust standard errors.

These results suggest some significant differences between irrigators in the Riverland and the GMID. This is probably a reflection of the different industry types within the two study regions and levels of water stress felt as outlined in section 2.1. The variables that explain the intensive, defensive and efficiency improvement strategies also differ considerably, implying that irrigators undertaking different strategies are influenced by different personal and property characteristics as well as different values and attitudes.

For Riverland irrigators, almost none of the farmer characteristics are significant explanatory variables for undertaking intensive or defensive strategies in the last five years. Farm characteristics, on the other hand, include a few significant variables that influence the extent of the intensive or defensive strategies. As Riverland irrigators are predominately grape growers, it is interesting to note that an increase in the percentage of the irrigated area planted in grapes is associated with a decrease in the extent of both intensive and defensive strategies. This implies that the higher the percentage of the irrigated land that is committed to wine grape production, the more likely it is that irrigators maintain constant strategies, which highlights the long-term nature of vines and the difficulty that grape growers experienced trying to stay alive during the drought.

Some positive results are that irrigators were able to undertake more intensive strategies if they have larger water entitlement and deploy more defensive strategies if they have a higher proportion of their household income from off- 
farm activities. Attitudes by Riverland irrigators to the environment are interesting: farmers who are looking to expand and are employing intensive strategies have positive attitudes to the environment and farmers' stewardship role; while those employing defensive strategies have less positive environmental attitudes. This could indicate that defensive irrigators are on their way out of farming and irrigation and feel under threat from environmental demand, while intensive irrigators intend to expand and remain in the industry in the long term and therefore may appreciate the need to resolve environmental issues in order for the industry to remain viable.

Table 3: $\quad$ South-eastern Australian Irrigator Strategies.

\begin{tabular}{|c|c|c|c|c|c|c|}
\hline & \multicolumn{2}{|c|}{ Intensive } & \multicolumn{2}{|c|}{ Defensive } & \multicolumn{2}{|c|}{ Efficiency Imp. } \\
\hline Variable & Riverland & GMID & Riverland & GMID & Riverland & GMID \\
\hline Age & 0.014 & $-0.043 * * *$ & -0.0004 & -0.015 & -0.027 & 0.005 \\
\hline Male & -0.150 & -0.043 & 0.309 & -0.153 & $0.636 * *$ & -0.13 \\
\hline Farmyears & -0.017 & $-0.022 * *$ & 0.011 & -0.001 & 0.002 & -0.015 \\
\hline Liveyears & 0.008 & $0.014 * *$ & 0.001 & -0.002 & $-0.014^{*}$ & 0.005 \\
\hline Yearsremain & 0.016 & -0.004 & 0.001 & -0.013 & 0.022 & 0.004 \\
\hline Farmfamily & 0.252 & -0.185 & 0.101 & 0.400 & -0.473 & -0.23 \\
\hline Lowedu & -0.168 & 0.172 & -0.167 & 0.214 & -0.279 & 0.23 \\
\hline Postg & -0.177 & 0.265 & -0.186 & -0.162 & $1.214 * *$ & -0.15 \\
\hline Successor & -0.020 & $0.360 * *$ & 0.147 & 0.106 & -0.011 & -0.222 \\
\hline Wfp & 0.155 & $0.554 * *$ & -0.227 & 0.100 & $0.992 * * *$ & 0.317 \\
\hline Farmsize & 0.489 & -0.239 & -0.064 & -0.194 & 0.725 & -0.048 \\
\hline Irrisize & 0.341 & -0.748 & -1.457 & -0.320 & 37.537 & 1.745 \\
\hline Tothwater & $0.564 *$ & $0.467 *$ & 0.327 & 0.265 & 2.461 & -0.068 \\
\hline Pgrape & $-0.010 * *$ & n.a. & $-0.005 * *$ & n.a. & 0.006 & n.a. \\
\hline Pfrunut & -0.008 & -0.012 & - & $-0.014 * *$ & 0.002 & -0.003 \\
\hline Pgrazing & n.a. & -0.007 & n.a. & -0.003 & n.a. & -0.004 \\
\hline Pseed & n.a. & 0.001 & n.a. & -0.004 & n.a. & 0.005 \\
\hline Pcereal & n.a. & 0.003 & n.a. & -0.006 & n.a. & 0.033 \\
\hline Landcare & -0.518 & 0.286 & $-0.611 * *$ & 0.158 & -0.094 & -0.05 \\
\hline waterwatch & 0.405 & 0.419 & -0.207 & 0.002 & $1.095 * *$ & 0.16 \\
\hline ftcomfarm & 0.099 & $0.738 * *$ & $0.440 * *$ & -0.037 & 0.368 & $0.910 * *$ \\
\hline offfarmincome & -0.002 & 0.001 & $0.006 * *$ & $0.007 * *$ & -0.0002 & -0.001 \\
\hline contfarming & 0.045 & $0.225 * * *$ & -0.032 & $-0.175 * * *$ & $0.186 * *$ & 0.058 \\
\hline info gov & $0.393 *$ & -0.149 & 0.071 & -0.147 & -0.12 & -0.02 \\
\hline info pri & 0.050 & -0.275 & -0.030 & 0.121 & 0.155 & -0.156 \\
\hline Drip & 0.032 & 0.945 & -0.128 & -0.285 & - & - \\
\hline Reuse & 0.002 & 0.001 & 0.003 & $0.005 * *$ & - & - \\
\hline Offfdr & 0.003 & -0.0003 & -0.003 & -0.002 & - & - \\
\hline f1 tradition & -0.141 & -0.031 & -0.113 & $0.176^{* *}$ & 0.009 & -0.072 \\
\hline f2 succession & -0.067 & -0.026 & -0.102 & -0.136 & $-0.345 * *$ & 0.096 \\
\hline f3 commercial & 0.029 & -0.099 & -0.085 & $0.150 *$ & 0.22 & -0.178 \\
\hline $\mathrm{f} 4$ environ & $0.217^{*}$ & -0.090 & $-0.222 * *$ & 0.037 & $-0.241 *$ & 0.143 \\
\hline f5 tech & 0.156 & -0.150 & -0.076 & 0.037 & $0.236^{*}$ & 0.177 \\
\hline cut1/constant & $1.689 *$ & -0.353 & 0.666 & $-1.606^{*}$ & 0.62 & 0.646 \\
\hline cut 2 & $2.630 * * *$ & 1.087 & $2.174 * * *$ & -0.111 & n.a. & n.a. \\
\hline No. Of Obs. & 259 & 262 & 259 & 262 & 260 & 268 \\
\hline Pseudo R2 & 0.14 & 0.20 & 0.14 & 0.11 & 0.38 & 0.27 \\
\hline Log likelihood & -117.29 & -149.28 & -204.31 & -234.86 & -60.04 & -72.93 \\
\hline
\end{tabular}

$* * *, * *, *$ signify significance level at $1 \%, 5 \%$ and $10 \%$ respectively.

n.a.: not applicable; - variable dropped due to multicollinearity (pfrunut) or possible endogeneity. 
Within the GMID, irrigators with future plans for their farm in terms of having a whole farm plan, having a successor in place, and expecting to continue farming for a long period of time were much more likely to have implemented intensive strategies in the past five years. The findings suggest that farmers deploying intensive strategies in GMID usually have large, well planned, commercially operated farms that would be passed on to the next generation. This result is quite different to the Riverland situation.

The issue of succession is difficult for many farmers, and Kuehne et al. [8] suggested that Riverland irrigators have not handled the issue well. This is illustrated by one irrigator's succession comments and their frustration over his parent's farm:

You start to get all those emotional things happening. ... We look after that property for them, manage it and do all the work because they are eighty year olds... we're not about to say to them well we're sorry you're out on your ear, you can't do that; but [they are] a generation of people who didn't do forward planning they did not think of generational change and it's incredibly difficult to talk about. We've been trying, trying to talk it through for fifteen years and it's not talked about, and seen as their private business.

Such a situation makes succession planning difficult, and the results of the GMID models suggest that the farm families which have sat down and planned how the succession should take place were more likely to have undertaken intensive strategies.

In both states, an increase in off-farm income meant that irrigators were much more likely to undertake defensive strategies, signalling that off-farm income is associated with farms selling land or water or reducing irrigation area. They may either be looking to just keep the farm afloat while they maintain their lifestyle or they may be preparing for exit. GMID irrigators who undertook defensive strategies were more orientated toward tradition issues, their defensive strategies are directed toward maintaining the farm and their lifestyle until retirement, and, hence, also linked to the findings related to off-farm work. To stay on the farm they are cashing in on farm assets and replacing farm income with off-farm income. GMID irrigators were less likely to undertake defensive strategies if they had a higher percentage of irrigation area planted in fruit or nut trees while the percentage in pasture and cereal crops do not appear to influence either intensive or defensive strategies. Yet again it reflects the differences between farmers with permanent plantings and cereal or broadacre farmers.

In the Riverland, both farmer (male, liveyears, postg, wfp, waterwatch and contfarming) characteristics and farmer attitudes (succession, environ and tech) influence the probability of having undertaken irrigation efficiency improvements in the last five years. It appears that decisions to improve irrigation efficiency are driven by education, farm planning and conservation awareness. For Riverland farmers, holding strong value orientations towards succession and the environment is negatively related to the likelihood of having undertaken efficiency improvements while a favourable attitude towards technology is positively related to having undertaken efficiency improvements. 
In the GMID, there was only one significant influence in the efficiency improvements model. Being a fulltime commercial farmer has a significantly positive influence on having undertaken efficiency improvements. Few significant explanatory variables in the GMID efficiency improvement model are in contrast to Liao and Martin's [9] study in 2006-08 on dairy farms that suggested farmer education, farm income and size were important determinants on farm innovation levels. However, this study was undertaken earlier than ours, and only utilized simple statistical analysis when making these suggestions. The severity of the continuing drought may have forced irrigators in GMID to make considerable more changes to their water practices. For example, Liao and Martin's [9] found that on average $42 \%$ of dairy farms had adopted new irrigation and water management practices, where we found that by early 2009 , $88 \%$ of our GMID respondents had adopted some sort of irrigation efficiency in the past five years. This indicates that continued drought has forced a large number of irrigators to improve their irrigation efficiency.

\section{Conclusions}

This study has investigated what drives the strategic intensive and defensive drought management choices of irrigators. In particular, we studied attack, defend and adopt strategies in two key irrigation regions: the Riverland of South Australia and the GMID in Victoria. Our results show that the influences on the employment of intensive and defensive strategies by irrigators were very different within the two regions reflecting the differences in production and past experience in managing fluctuating supply. This indicates a disparity of influences on irrigator drought management strategies including both personal and property characteristics as well as values and attitudes. The type of production also plays an important role in influencing irrigators' intensive, defensive or adopting strategies. Farmers who seem to have a well planned and long term view of their farms, in terms of having a whole farm plan, having a succession strategy and planning to be continuing farming in the long-term, tend to be more responsive to the drought conditions by deploying more intensive strategies. On the other hand, there is some evidence that farmers with negative environmental attitudes and higher off-farm income are more likely to be deploying more defensive strategies.

Our paper provides some direction in understanding the main drivers of farmers' responses to difficult external environmental conditions and it offers useful policy implications for how to best assist farmers with structural adjustment. Nevertheless, this paper does not provide any indication on how different strategies in general influence farm viability. Future research investigating how these strategies influence farm viability would be beneficial.

\section{References}

[1] DEWHA, Small Block Irrigators Exit Package, 2009. http://www.environment.gov.au/water/publications/mdb/pubs/small-blockirrigators-fact-sheet.pdf 
[2] Wong, P., Victorian farmers eligible for drought exit grants, 2009. http://www.climatechange.gov.au/ /media/Files/minister/wong/2009/mediareleases/February/mr20090203.ashx

[3] Brennan, D., Water Policy Reform in Australia: Lessons from the Victorian Seasonal Water Market. Aust. J. Agric. Res. Econ., 50, pp. 403-423, 2006.

[4] Thompson, D., Jackson, D. \& Powell, R., Analysing Drought Strategies to Enhance Farm Financial Viability: Final Report, prepared for the Land and Water Resources Research and Development Corporation and the Rural Industries Research and Development Corporation, by NSW \& WA Departments of Agriculture and the Centre for Agricultural and Resource Economics, University of New England Armidale, 1996.

[5] David, F.R., Strategic Management Concepts and Cases, $12^{\text {th }}$ ed., Prentice Hall, Upper-Saddle River, NJ, 2009.

[6] Lane-Miller, C., Zuo, A., Bjornlund, H. \& Wheeler, S., Values, Attitudes and Beliefs held by South Australian and Victorian Irrigators in a Time of Drought. Proc. of the sixth International Conference on Water Resources Management, eds. C. A. Brebbia \& V. Popov, WIT Press: Southampton, 2011,

[7] Greene, W., Econometric Analysis, Pearson Education Inc, New Jersey, 2008

[8] Kuehne, G. Bjornlund, H. and Loch, A. 2010, An investigation of farmers' non-profit decision drivers during a period of extreme stress, Rural Industries Research and Development Corporation research report 10/075, June.

[9] Liao, B \& Martin, P 2009, Farm innovation in the broadacre and dairy industries, 2006-07 to 2007-08, ABARE, Canberra. 